\title{
Colonia Gemella/Gemina Iulia Lampsacena: Anadolu'nun Kuzeybatısından Kısa Ömürlü Bir Roma Kolonisi
}

\author{
Erdinç BURULDA $\breve{G}^{1}$
}

Atıf/C): Buruldağ, Erdinç, , Colonia Gemella/Gemina Iulia Lampsacena: Anadolu'nun Kuzeybatısından Kısa Ömürlü Bir Roma Kolonisi, Artuklu İnsan ve Toplum Bilim Dergisi 2020/5 (2), 15-23.

Öz

MÖ 1. yüzyıl ikinci yarısının hemen başındaki Roma kolonizasyon faaliyetleri neticesinde Anadolu'nun kuzeybatısında yer alan iki Grek kentine, eş zamanlı olarak koloni statüsü verilmiştir. Troas olarak bilinen bölgedeki bu kentler, Parion ve Lampsakos'tur. Her iki kent de konumları itibariyle önemli bir geçiş noktasında yer alıyor olmaları yanında, olasılıkla sahip oldukları zengin maden yatakları ve verimli arazileri sebebiyle birer Roma kolonisine dönüştürülmüştür. Mevcut veriler, Parion'un koloni statüsünün en azından üç asır sürdüğünü, Lampsakos’taki koloninin oldukça kısa ömürlü olduğunu göstermektedir. Nümismatik kanıtlardan yani koloni sikkelerinden anlaşıldığı kadarı ile ismi muhtemelen Colonia Gemella/Gemina Iulia Lampsacena olarak değişen Lampsakos'un Roma koloni statüsü, yarım asırlık bir süreç içerisinde sonlandırılmış olmalıdır. Kentteki koloni statüsü her ne kadar kısa bir zaman dilimini kapsamış olsa da eldeki verilerle, bu yeni siyasi yapılanma ve İtalik kökenli yeni yerleşimcilerle birlikte Roma kültüründen birtakım unsurların Lampsakos'a taşınmış olduğunu söylemek mümkündür. Bu çalışma, Lampsakos'un, Roma koloni statüsünün kanıtlarını ortaya koymayı ve kentin bu statüyü neden koruyamadığı sorusuna yanıt aramayı amaçlamıştır.

Anahtar Kelimeler: Lampsakos, Colonia Gemella/Gemina Iulia Lampsacena, Koloni, Sikke.

\section{Colonia Gemella/Gemina Iulia Lampsacena: A Short-Lived Roman Colony from Northwestern Anatolia}

Atıf/C): Buruldağ, Erdinç, Colonia Gemella/Gemina Iulia Lampsacena: A Short-Lived Roman Colony from Northwestern Anatolia, Artuklu Human and Social Science Journal 2020/5 (2), 15-23.

\section{Abstract}

Two ancient Greek cities, situated in northwestern Anatolia known as Troad in ancient times, were simultaneously turned into a Roman colony, as a consequence of the Roman colonization activities taking place at the beginning of the second half of the 1st century BC. These cities are Parium and Lampsacus. Both of them became a Roman colony, probably because of their geopolitical position, rich mineral deposits, and fertile lands. The existing data indicate that Parium's colony status lasted for at least three centuries; Lampsacus' colony status was rather ephemeral. Numismatic evidence suggests that the name of the city Lampsacus probably changed to Colonia Gemella/Gemina Iulia Lampsacena and the colony status of Lampsacus must have been terminated within a half-century. Even though Lampsacus' colony status lasted for only a short time, the existing data from this period points out that some elements of the Roman culture were transported to the city by colony status and Roman colonists. This article aims to present evidence of the Roman colony in Lampsacus and answer the question of why the city lost its colonial status in a short time.

Keywords: Lampsakos, Colonia Gemella/Gemina Iulia Lampsacena, Colony, Coin.

${ }^{1}$ Dr. Öğretim Üyesi Erdinç BURULDAĞ, Çankırı Karatekin Üniversitesi, Edebiyat Fakültesi, Arkeoloji Bölümü, erdincburuldag@hotmail.com, ORCID: orcid.org/0000-0003-3075-5503.

Bu çalışma 18-20 Nisan 2019 tarihinde Alanya Keykubat Üniversitesi ev sahipliğinde düzenlenen "6. Uluslararası Sosyal, Beşeri ve İdari Bilimler Sempozyumu" çerçevesinde bildiri olarak sunulmuștur.

Geliş/Received: 03.11.2020, Kabul/Accepted: 19.11 .2020 


\section{GíRIŞ}

Antik dönemde Troas olarak adlandırılan Anadolu'nun kuzeybatısı, jeopolitik konumu, yeraltı ve yerüstü zenginlikleri ile tarihin hemen her döneminde yoğun iskân gören bölgelerin başında gelmiştir. Süreç içerisinde farklı kültürleri bir araya getirmiş olsa da antik dönemde Troas'ta Hellen kültürünün baskın olduğu aşikârdır. Kuşkusuz bunda, MÖ 1. bin yıl başından itibaren bölgeye yerleşmeye başlayan Aiol toplulukları ve kolonizasyon hareketleri etkin rol oynamıştır. Aynı bin yılın sonlarında ise bölge, Romalılar tarafından kolonize edilir. Yarım asırlık bir süreçte gerçekleşen bu kolonizasyon faaliyetleri sonucunda Troas'ın kuzeybatısındaki kıyı kentleri, Lampsakos, Parion ile bölgenin batı sahilindeki Alexandria Troas, birer Roma kolonisine dönüştürülür. Mevcut veriler, bu dönemde olasılıkla Colonia Gemella/Gemina Iulia Lampsacena ismi ile anılan Lampsakos’un koloni statüsünün diğer iki koloninin aksine, oldukça kısa sürmüş olduğuna işaret etmektedir.

Bu çalışmanın amacı, Anadolu'nun kuzeybatı ucunda bulunan Lampsakos'un Roma koloni statüsüne ilişkin bilinen tüm kanıtları ortaya koyarak, bunlar ışığında koloninin kısa ömürlü olma gerekçesini irdelemektir.

\section{Koloni Statüsü ve Sürecine Dair Kanıtlar}

Anadolu'nun kuzeybatısındaki iki Roma kolonisinden biri olan Colonia Gemella/Gemina Iulia Lampsacena, yeni kurulan bir kentten öte, yerleşimcileriyle birlikte hâlihazırda mevcut olan Lampsakos'a verilen koloni statüsünün en somut kanıtı yani yeni siyası oluşum ile kentin değişen ismidir. Coğrafi konumu itibariyle Hellespontos'un Propontis'e varmadan önce, daraldığı kısımda bulunan bu yerleşim, günümüzde Çanakkale ili, Lapseki ilçesi sınırları içerisindedir. Troas’ın köklü Grek yerleşimlerinden biri olan Lampsakos, MÖ 7. yüzyıl ikinci yarısında kurulmuş olmalıdır. Yeraltı ve yerüstü kaynaklarıyla, bölgenin zengin kentlerinden biri olma özelliğini tarihsel süreç içerisinde koruyan bu yerleşim, MÖ 1. yüzyıl ikinci yarısı başlarında bir Roma kolonisine dönüştürülmüştür (Buruldağ, 2017a: 11-23; Buruldağ, 2017b: 76-79).

Lampsakos'un Roma koloni statüsüne ilişkin en somut kanıtları, nümismatik veriler oluşturmaktadır. Latince lejantlı sikkelerden oluşan bu verilerin ilk örnekleri, Imhoof-Blumer ve Babelon'un 19. yüzyılın sonlarında ve Robinson'un 20. yüzyılın başlarında yapmış oldukları nümismatik çalışmalarında değerlendirilmiştir. Bahsi geçen araştırmacıların yaptığı bu çalışmalarda, Iulius Caesar Dönemi'ne yani MÖ 46/45 yıllarına tarihli, Latince lejantlı sikkeler, Troas'ın kuzey yerleşimlerinden biri olan Parion'a atfedilmiştir. Bunun en önemli sebebi, Parion'un da aynı yıllarda bir Roma kolonisi olması ve bu sikkeler ile aynı tarihlerde darp edilmiş olan Parion koloni sikkelerinin benzerlik göstermesiydi. Sikkeler arasındaki bu benzerlik, onların ön yüzlerinde yer alan dört harflik bir lejanttan ibaretti. Parion'a ait olduğu öngörülen sikkelerdeki, koloni isminin baş harflerini simgeleyen bu lejant, "C.G.I.P” iken, söz konusu sikkeler üzerinde "C.G.I.L" harfleri bulunmaktaydı. Her iki lejanttaki son harfin farklı oluşu, araştırmacılar tarafından olasılıkla hem farklı kondisyondaki sikkeler üzerinde yer alıyor olmaları nedeni ile okunamamaları hem de Lampsakos'un o dönemlerde bir Roma kolonisi olabileceği ihtimali üzerinde durulmaması sebebiyle ayırt edilememiş olmalıdır. Bunun sonucunda da "C.G.I.L” harflerini içeren bazı sikkelerin Parion'a ait olduğu önerisinde bulunulmuştur (Imhoof-Blumer, 1883: 252, No. 127-130; Imhoof-Blumer, 1884: 296; Babelon, 1898: No. 930-931; Robinson, 1921: 7-8, No. 6-7). Yaklaşık çeyrek asır sonra, lejantlar arasındaki bu ayrımı fark eden Grant, son harf olan "L" karakterinin, bir Roma kolonisine dönüşen eski yerleşim ismine ait olması gerektiği fikrinden hareketle, sikkelerin Parion yerine, onun komşusu olan Lampsakos'a ait olduğu görüşünü ortaya atar (1946: 246). Onun bu önerisi bilim çevrelerince kabul görür ve günümüzde halen yapılmakta olan nümismatik çalışmalarında da bu 
sikkelerin Lampsakos'a ait olduğu ifade edilmektedir (RPC 1, No. 2268-2272; Tek-Arslan, 1996: 25, No. 133; SNG France 5, Mysia, No. 1260-1262; SNG Turkey 3, Çanakkale, No. 68-69).

Lampsakos’un bir Roma kolonisine dönüştüğü öngörüsünü destekleyen bir başka kanıtı, antik yazarlardan Appianus'un tarihe düştüğü bir notta bulmaktayız. Onun günümüze taşıdığı anekdotundan anlaşıldığı üzere, Iulius Caesar, çok sayıda İtalik kolonisti Lampsakos'a iskân ettirmiş ve bu yeni yerleşimciler, süreç içerisinde taraf değiştirerek Sextus Pompeius'un safına geçmiştir. Bu sayede kentten sağladığı iki yüz süvari ve piyadelerden oluşan üç lejyon ile Sextus Pompeius, karadan ve denizden Kyzikos'a saldırabilmişti (Appianus, Bella Civilia 5.137). Appianus'un bu ifadesi, Latince lejantlı sikkeler ile paralellik gösterirken, Lampsakos'un Iulius Caesar Dönemi'nde, MÖ 46/45 yılı ile Roma koloni statüsü elde etmiş olduğunu kanıtlar niteliktedir. Yine aynı ifadedeki önemli bir ayrıntı ve Augustus Dönemi'ne tarihli sikkeler ile gözlemlenen bazı değişimler, Colonia Gemella/Gemina Iulia Lampsacena'nın yani Lampsakos'un koloni statüsünün ilk on y1lı tamamlamasının ardından gelen hatalı bir askeri hamle neticesinde, kısa bir süre içerisinde siyasi bir yaptırıma uğrayarak koloni statüsünün sonlandırılmış olduğuna işaret etmektedir.

\section{Roma Koloni Statüsünün Lampsakos’taki Yansımaları}

Kolonizasyon dönemine ilişkin verilerden anlaşıldığ kapsamasına rağmen, Roma koloni statüsü, Lampsakos'un bir Grek polisinden Roma kolonisine dönüşümünde kentte birtakım değişimlere sebebiyet vermiştir. Arkaik dönemin başında kurulmuş olan ve Aiol kökenli halklarca iskân edilen bu köklü yerleşim, her alanda mevcut yapısını koruyabilmişse de Roma kolonizasyonuyla birlikte, Latin karakterli kent ismi ile yeni bir döneme girmiştir. Her ne kadar mevcut verilerle koloni ismi açık bir şekilde belirlenemese de yerleşime atfedilen MÖ 46/45 yıllarına tarihli, Latince lejantlı Iulius Caesar sikkelerindeki "C.G.I.L" harflerinden hareketle (Imhoof-Blumer, 1883: 252, No. 127-130; Imhoof-Blumer, 1884: 296; Babelon, 1898: No. 930-931; Robinson, 1921: 7-8, No. 6-7; Grant, 1946: 246; RPC 1, No. 22682272; SNG France 5, 1260-1262), onun, “Colonia Gemella/Gemina² Iulia Lampsacena” olduğu önerisi bilim çevrelerince kabul görmektedir (Grant, 1946: 246-248, 461; Robert - Robert, 1950: 86-89; Vittinghoff, 1952: 88, dn. 1; Frisch, 1978: 139; Laffi, 2004a: 240, 244; Laffi, 2004b: 159; Laffi, 2007: 155, 160-161, 181; Galsterer-Kröll, 1972: 68, 131, No. 421; Henderson, 1953: 141; Bögli, 1966: 7, dn. 22; Esch, 2008: 206, dn. 51; Camia, 2010: 369; Römhild, 2011: 159-160, 168; Buruldağ, 2017a: 35-36; Buruldağ, 2017b: 79-81).

İlk koloni darpları, aynı zamanda yerleşimin yeni siyasi yapılanmasına dair kanıtları da günümüze taşımaktadır. Ön yüzlerinde yeni siyasi statünün sembolünü yani koloni isminin baş harflerini taşıyan sikkelerin arka yüzlerinde ise "Q LVCRETI L PONTI IIVIR M TVRIO LEG" (Imhoof-Blumer, 1884: 296, No. 155; Babelon, 1898: No. 930-931; Grant, 1946: 246, No.1, 4; RPC 1, No. 2268, 2270, 2272; Tek-Arslan, 1996: 25, No. 133; SNG France 5, Mysia, No. 1260-1261; Katsari - Mitchell, 2008: 234; SNG Turkey 3, Çanakkale, No. 68) ve "Q LVCRET L PONT IIVIR COL DED PR" (Robinson, 1921: 7-8, No. 6-7; Grant, 1946: 246, No. 2, 5-6; RPC 1, No. 2269, 2271, 2273; SNG France 5, Mysia, No. 1262; Katsari - Mitchell, 2008: 234; SNG Turkey 3, Çanakkale, No. 69) lejantları bulunur. Söz konusu sikkeler üzerindeki bu lejantlarda, açık bir şekilde, koloninin en üst yöneticileri olan duumvirlerin isimlerine yer verilmiştir.

Roma Dönemi'ne tarihli mevcut epigrafik verilere yani yazıtlara bakıldığında, bunların tamamının Grekçe olduğu fark edilir. İçerik olarak bu yazıtların \%73'ü mezar yazıtları, \%18'i onurlandırma yazıtları ve \%'u ise dini yazıtlardan oluşmaktadır (Frisch, 1978). Yine yazıt ve

2 Koloni isminin kısaltması olan harflerden biri “G” için ağırlıklı görüș, onun “Gemella/Gemina” kelimelerinden birini simgelediği yönünde olsa da bir diğer varsayım Henderson (1953: 141), Bögli (1966: 7, dn. 22) ve Esch (2008: 206, dn. 51) tarafından ifade edilir. Bu araștırmacılara göre söz konusu harf, "Genetiva” kelimesinden gelmekteydi. 


\section{Roma Kolonisi}

sikkeler aracılığıyla saptanmış olan isimlerin \%79’u Grek, \%21'i ise Latin kökenlidir (Buruldağ, 2017a: 46-56). Epigrafik verilerle desteklenmese de Appianus'un bahsettiği üzere, Lampsakos’taki kolonistlerin iki yüz süvari ve piyadelerden oluşan üç lejyon oluşturabilmiş olması (Bella Civilia 5.137), mevcut nüfus yapısı içerisinde Roma kökenli yurttaşların azımsanmayacak derecede bir yoğunluğa sahip olduğunu düşündürmektedir.

Lampsakos'un koloni sikkeleri, aynı zamanda üzerlerinde kültürel etkileşimi sağlayacak yeni öğeleri de barındırmaktaydı ki bunlardan bazıları koloni statüsünün sonlandırılmasından sonra da kent sikkeleri üzerinde bir süre daha yer almaya devam etmiştir. Roma kültürü ile doğrudan ilişkili olan bu sikke tipleri, "Saban Süren Rahip" (Babelon, 1898: No. 930-931; Grant, 1946: 246, No. 1 2; SNG France 5, Mysia, No. 1260-1262; RPC 1, No. 2268-2269; SNG Turkey 3, Çanakkale, No. 69), “Cornucopia” (Grant, 1946: 246, No. 6; RPC 1, No. 2271; SNG v. Aulock 1957, 1306; SNG v. Aulock 1967, 7410; BMC Mysia, s. 89, No. 87; SNG Turkey 3, Çanakkale, No. 69, 80-81, 85, 87), “Capricorn/Keçi Betimleri” (SNG Turkey 3, Çanakkale, No. 75, 79-80, 82-83, 88), "Pruva” (Grant, 1946: 246, No. 4-5; SNG Cop. Mysia, No. 241; RPC 1, No. 2272-2273; SNG Turkey 3, Çanakkale, No. 85, 87) ve "Senato" (RPC 1, No. 2278; Martin, 2013a: 98, Abb. 37a-d; Martin, 2013b: 20) betimlerinden oluşur.

Lampsakos antik kenti, günümüzdeki modern Lapseki yerleşiminin tam altında kaldığg için tamamen tahrip olmuştur. MS 4. yüzyıl ortalarına kadar ayakta kalabilen eski tapınakların ve olasılıkla kamu yapılarının, İmparator II. Konstantius'un emri ile sökülerek, devrin Konstantinopolis yani İstanbul'una taşınmış olduğu da bilinmektedir (Frisch, 1978: 140). Kente gelmiş olan seyyahlar arasında sadece Castellan, antik yerleşime dair görebildiklerini tanımlamış ve bunları bir plan üzerine işlemiştir. Bu sebepten ötürü onun çizimleri ve notları son derece önemlidir. Castellan'ın 1820 yılında, yerleşimde karşılaştığı antik kalıntılar, liman yapısı, aquadükt hattı ve Priapos tapınağ olduğunu düşündüğü yapı kalıntıları, sütunlar ve bloklardan ibarettir (1820: 253-288). Son yıllarda Lapseki ve çevresindeki gerçekleştirilen kazı çalışmaları ve yüzey araştırmaları da antik kenti Roma Dönemi ve sonrasına 1şık tutmaktadır. Bu araştırmalarda Roma Dönemi'ne tarihli lahit mezarlara (Körpe, 1998: 171-194; Körpe - Treister, 2002: 429-450; Arslan, 2007: 174) ve olas1 savunma duvarı kalıntıları (Arslan, 2009: 335) ile Lampsakos’un Geç Antik Çağ'daki yerleşim izlerine ve buradaki şarap üretimine dair bulgulara (Koçyiğit - Esirgemez, 2016: 451-477) rastlanmıştır.

Bir Grek polisi olarak Lampsakos ismine, MÖ 75 yılına tarihli Ephesos Gümrük Kanunu’nda rastlanmaktadır (Engelmann - Knibbe, 1986: 19-32; Engelmann - Knibbe, 1989). Troas'ın bazı yerleşimlerinin de zikredildiği bu önemli epigrafik veri, Lampsakos'un kent limanının, içerisinde Roma'nın bir gümrük ofisi ile MÖ 1. yüzyıl ilk yarısında faal olduğunu ve aynı zamanda yerleşimin bundan ekonomik olarak çıkar sağladığını göstermektedir.

Eldeki veriler ile Roma koloni statüsüne değin Lampsakos’ta kent kurucusu Lampsake, Dionysos, Asklepios, Apollon ve Athena Kültleri'nin varlığından söz edilebilir (Buruldağ, 2017a: 103-107). Bunların yanı sıra yerleşimde belirgin biçimde, köklü bir Priapos Kültü ile Athena Kültü olduğu ve bunların Roma'nın resmi din olarak Hıristiyanlığı kabul ettiği sürece değin sürdürüldüğü anlaşılmaktadır (Buruldağ, 2017a: 110-126). Kolonizasyon sürecini takiben kentte gözlemlenmeye başlayan kültler ise Livia Augusta ve İmparatorluk Kültü'nden oluşmaktadır. Kente atfedilen Grekçe bir yazıtta (Frisch 1978, 74-76, No. 11), Livia Augusta'ya "Hestia" ve "Yeni Demeter" olarak hitap edilirken metnin dördüncü satırında geçen "agalma” kelimesinin İmparatorluk Kültü ile ilişkili bir tapınakta yer alan İmparatorluk heykeli için kullanıldığı, Price tarafından önerilmektedir (2004: 292).

Eldeki tüm bu kanıtlarla, her ne kadar kısa ömürlü de olsa Colonia Gemella/Gemina Iulia Lampsacena’nın, isim değişikliği başta olmak üzere mevcut Lampsakos yerleşimi ve yerleşimcileri 


\section{E. BURULDA $\breve{G}$}

üzerinde siyasi, demografik, kültürel ve dini anlamda birtakım etkiler bırakmış olduğunu söylemek yanlış olmayacaktır.

\section{Koloni Statüsünün Sonlandırılışı ve Buna İlişkin Öneriler}

Lampsakos'taki bahsi geçen ilk koloni darplarını ardından, sikkelerdeki Latince lejantlar, bir daha görülmemek üzere ortadan kaybolur ve Augustus Dönemi ile sikkelerde sadece Grekçe lejantlara rastlanır. Bunun yanı sıra, Grekçe lejantlı bu sikkelerde yerleşimin etnisitesi, önceki dönemlerdeki gibi, " $\Lambda \mathrm{AM} "$, " $\Lambda \mathrm{AM \Psi ",} \mathrm{"} \Lambda \mathrm{AM} \Psi \mathrm{AKH}$ " ve " $\Lambda \mathrm{AM} \Psi \mathrm{AKHN} \Omega N$ " ifadeleri ile belirtilmektedir. Dolayısıyla sikkeler üzerindeki bu uygulamalar, Lampsakos'un koloni statüsünün Augustus Dönemi ya da hemen öncesinde sonlandırılmış olduğuna işaret eder (Grant, 1946: 247; Robert - Robert, 1950: 86-89; Vittinghoff, 1952: 88-89; Frisch, 1978: 139; RPC 1, 386; Freber, 1993: 145; Tenger, 1999: 165; Laffi, 2004a: 240; Laffi, 2004b: 159; Esch, 2008: 206; Filges, 2010; 135; Römhild, 2011: 168; Martin, 2013a: 99; Filges, 2016: 31; Buruldağ, 2017a: 35-43; Buruldağ 2017b: 83). Roma Dönemi'ne tarihli mevcut epigrafik verilerin tamamının Grekçe oluşu da bu görüşü destekler niteliktedir.

Antik yazarlardan Plinius, bir anekdotunda, Troas'in kuzey yerleşimlerini sayarken sadece Parion için koloni ifadesini kullanmış; Lampsakos'u ise eski ismi ile belirtmiştir (Naturalis Historia V.141). Strabon'da da bu türden bir ifadeye rastlanmaktadır. Örneğin Alexandria Troas'ın uzun ömürlü bir yerleşim olduğundan bahsedilirken onun bir Roma kolonisi olduğuna vurgu yapılmış ancak bölgedeki diğer kentlerle birlikte anılan Lampsakos için sadece "polis" ifadesi kullanılmıştır (Strabon, Geographika XIII.1.18). Her iki antik yazarın bu ifadeleri, kentin en azından MS 1. yüzyıl ikinci yarısından önce koloni statüsünü yitirmiş olduğu varsayımını güçlendirmektedir.

Bu noktada, Iulius Caesar tarafından kurulan koloninin, Augustus Dönemi'nde ya da onun hemen öncesinde koloni statüsünü neden yitirdiği sorusuna yanıt aranmalıdır. Iulius Caesar tarafından Roma kolonisine dönüştürüldüğü bilinen kentler, Lampsakos, Parion, Apamea, Herakleia Pontika ve Sinope'dir (Vittinghoff, 1952: 87-88; Filges, 2010: 135; Filges, 2016: 29). Bunlar arasında Lampsakos ve Herakleia Pontika'ın koloni statüleri, diğerlerine göre oldukça kısa sürmüştür.

Lampsakos’taki Roma kolonisinin varlığına dair bilinen son tarih, MÖ 35 yılıdır. Bu tarihte Lampsakos'ta yaşayan Romalı kolonistler saf değiştirmiş ve Sextus Pompeius'un tarafına geçmiştir. $\mathrm{Bu}$ kolonistlerden sağlanan askeri destek ile Pompeius, Kyzikos'a karadan ve denizden saldırabilmişti (Appianus, Bella Civilia 5.137). Tenger (1999: 165) ve Römhild'in (2011: 168) de belirttiği üzere bu olayın ardından Lampsakos, olasılıkla Octavianus/Augustus tarafından cezalandırılarak koloni statüsü düşürülmüş olmalıdır.

Herakleia Pontika'da da benzer bir durum yaşanmış ve MÖ 31 yılında, kolonide yaşayan Romalılar bir gecede katledilmiştir (Strabon, Geographika XII.3.6). Bu olayı takiben, Augustus Dönemi'yle birlikte Herakleia Pontika'nın koloni statüsünün devam ettiğine işaret eden herhangi bir kanita rastlanmaz 3 (Jonnes, 1994; Esch, 2008: 203, dn. 27). Dolayısıyla, söz konusu hadise, Herakleia Pontika'daki Roma kolonisinin sonlandırılış nedeni olabilirdi. Asia Eyaleti'nin özgür kentlerden biri olan Kyzikos'ta da benzer bir olay yaşanmış ve yerleşimdeki Roma yurttaşları öldürülmüştü. Bu sebepten ötürü Kyzikos, Augustus tarafından cezalandırılmış ve kentin "özgür polis" statüsü beş yıl süre ile askıya alınmıştı (Levick, 1996: 648-649).

\footnotetext{
${ }^{3}$ Jonnes tarafından derlenen Herakleia Pontika yazıtları arasında MS 1. ve 2. yy'a tarihli 1, 3 ve 5 numaralı yazıtlarda "demos" ve "boule" kelimeleri geçmektedir. MS 4. yy sonlarına tarihli 6 numaralı Latince yazıt dışında mevcut tüm yazıtların Grekçe oluşu da Lampsakos'taki epigrafik kanıtlarla benzerlik gösterir.
} 


\section{Roma Kolonisi}

Provincia Hispania Ulterior Baetica'da kurulmuş olan Corduba kolonisi ise ilginç bir şekilde Lampsakos ile aynı kaderi paylaşmıştır. MÖ 2. yüzyıl ortalarında kurulmuş olan bu koloni (Jiménez - Carrillo, 2011: 55-58), kısa bir süre için Sextus Pompeius tarafından ele geçirilerek, MÖ 45 yılında Iulius Caesar'a karşı kullanılmıştır. Munda Savaşı sonucunda Pompeius ve ordusunu yenilgiye uğratan Iulius Caesar, Corduba'yı da yerle bir etmiştir. Savaşın hemen ardından Iulius Caesar ve Augustus'un Roma kolonizasyon faaliyetleri çerçevesinde bu koloni, yeni yerleşimciler ve Colonia Patricia ismi ile yeniden kurulmuştur (Reid, 1913: 232; Jiménez - Carrillo, 2011: 66). Günümüze ulaşan resmi kayıtlardan anlaşıldığı üzere koloninin eski ismi olan Corduba ise damnatio memoriae uygulaması ile silinmiştir (Jiménez - Carrillo, 2011: 66).

Lampsakos'un Roma koloni statüsünün sonlandırılış sebebine dair kesin bir kanıya varılamasa da mevcut veriler bu kararın Octavianus/Augustus tarafından verildiğine işaret etmektedir. Yine Augustus Dönemi'nde kolonizasyon faaliyetlerinin sürdürülmesi ve farklı coğrafyalarda yeni kolonilerin kurulması da eldeki verilerle paralellik gösterir. Diğer taraftan, olasılıkla aynı dönemde, Troas'ın batı ucundaki Alexandria Troas'ın da bir Roma kolonisine dönüştürülmesi ile yüzölçümü bakımından büyük sayılamayacak olan bölgede üç koloninin mevcudiyetinin gerekli görülmediği ve bunun sonucunda hâlihazırda birbirine oldukça yakın konumları sebebi ile Lampsakos ve Parion kolonileri arasından birinin tercih edilmiş olabileceği varsayımında da bulunulabilirdi. Ancak her ne kadar askeri nitelikli koloniler de olsa Pisidia ve çevresinde Augustus Dönemi'nde birbirine yakın konumda beş Roma kolonisinin kurulmuş olması, bu olasılığı desteklememektedir.

Kolonilerin kuruluş amaçları dikkate alındığında, onların kısa bir süreden ziyade, uzun vadede Roma'nın çıkarları doğrultusunda kurulmuş oldukları görülmektedir. Bu yüzden, yerleşimlerin koloni statülerinin feshedilişleri de aslında Lampsakos ve bahsi geçen diğer kentlerde olduğu gibi olağandışı bir durum neticesinde gerçekleşmiş olmalıydı. Troas’ta kurulmuş olan diğer iki Roma kolonisinin yani Parion ve Alexandria Troas'ın koloni statüsünün en azından üç asır varlığını sürdürmüş olması da bu varsayımı güçlendirmektedir.

\section{SONUÇ}

Roma kolonizasyon politikası kapsamında, Anadolu'nun farklı bölgelerinde kurulan kolonilerden biri olan Colonia Gemella/Gemina Iulia Lampsacena, antik dönemde Troas'ın kıyı yerleşimlerinden Lampsakos'ta, günümüzde ise Çanakkale'nin Lapseki ilçesinde bulunmaktadır. Bölgenin köklü Grek yerleşimlerinden biri olan Lampsakos’ta MÖ 46/45 y1llarına tarihli, Latince lejantlı sikkeler, kentin Iulius Caesar tarafından bir Roma kolonisine dönüştürüldüğünün en somut kanıtlarıdır. Aynı sikkeler üzerindeki dört harften oluşan lejant da bu koloninin baş harflerini yani olasılıkla Colonia Gemella/Gemina Iulia Lampsacena ismini sembolize etmektedir. Bu nümismatik verilerin yanında antik yazarlardan Appianus'un bir anekdotu da kentin koloni statüsünü dolaylı olarak belirtmektedir. Augustus Dönemi'ne gelindiğinde, Lampsakos sikkeleri üzerinde Latince yerine Grekçe lejantlar; koloni isminin kısaltması yerine, tıpkı Roma Dönemi öncesindeki dönemlerdeki gibi, Lampsakos ve onun sakinlerini ifade eden lejantlar kullanılmaya başlar. Augustus Dönemi’ni takiben bu uygulamanın sürdürüldüğü görülmektedir. Sikkelerin yanında, kente atfedilen epigrafik verilerde de herhangi bir Latince yazıt bulunmamaktadır. Dolayısıyla mevcut veriler, Anadolu'nun kuzeybatı ucundaki Lampsakos'un Roma koloni statüsünün kısa ömürlü olduğunu kanıtlar niteliktedir. Her ne kadar yarım asırlık süreç içerisinde koloni statüsü sonlansa da kentte, siyasi, sosyo-kültürel ve dini açıdan Roma izlerine rastlanmaktadır.

Gerekçesi tam olarak bilinmese de Lampsakos’un koloni statüsünün kaderini askeri ya da siyasi bir tavır belirlemiş olmalıdır. Appianus’un kentin bir Roma kolonisi olduğuna işaret eden ifadeleri, aynı zamanda olasılıkla koloninin kısa ömürlü olma sebebini de günümüze taşımış olur. 


\section{E. BURULDA $\breve{G}$}

Koloniye yerleştirilen İtalik kökenli yeni yerleşimciler, Sextus Pompeius'a askeri destek sağlayınca, Kyzikos kenti ve Herakleia Pontika ile Corduba kolonilerinin başına geldiği gibi Lampsakos da kısa süre içerisinde siyasi bir yaptırıma uğramış ve koloni statüsü sonlandırılmış olmalıdır.

\section{KAYNAKÇA}

Appianus, Appian's Roman History, çev. H. White (1912-1913), London: The Loeb Classical Library.

Arslan, N. (2007). Antik Çağda Lampsakos/Lapseki. Lapseki Sempozyumu, 23-24 Haziran 2007. Çanakkale. s. $167-174$.

Arslan, N. (2009). 2007 Yılı Lampsakos/Lapseki, Abydos ve Çan Yüzey Araştırması. Araşstırma Sonuçları Toplantısı, S. 26, C. 1, s. 333-344.

Babelon, E. (1898). Inventaire Sommaire de la Collection Waddington, Acquise par l'etat en 1897. Bibliothèque Nationale, Département des Médailles et Antiques. Paris: C. Rollin et Feuardent.

BMC Mysia. Wroth, W. W. (1964). Catalogue of The Greek Coins of Mysia. Bologna: Arnold Forni Editore. Strübys Erben.

Bögli, H. (1966). Studien zu den Koloniegründungen Caesars. Basel: Buchdruckerei R.M.

Buruldağ, E. (2017a). Anadolu'nun Romalılaşma Sürecinde Troas Bölgesi Kolonileri. Yayımlanmamış Doktora Tezi, Ankara: Ankara Üniversitesi Sosyal Bilimler Enstitüsü.

Buruldağ, E. (2017b). Lampsakos’ta Kurulan bir Roma Kolonisi: C.G.I.L. Anadolu/Anatolia, S. 43 , s. $75-90$.

Camia, F. (2010). Le Tribù Romane nelle Colonie d'Asia Minore. Le Tribù Romane: Atti della XVI e Rencontre sur l'épigraphie (Ed. M. Silvestrini). Bari: Edipuglia Editrice. s. 367-371.

Castellan, A. L. (1820). Lettres sur la Morée: l'Hellespont et Constantinople 2. Paris: Chez A. Nepveu Libraire.

Engelmann, H. - Knibbe, D. (1986). Das Monumentum Ephesenum. Ein Vorbericht. Epigraphica Anatolica, S. 8, s. 19-32.

Engelmann, H. - Knibbe, D. (1989). Das Zollgesetz der Provinz Asia. Epigraphica Antolica, S. 14. Bonn: Rudolf Habelt Verlag.

Esch, T. (2008). Zur Frage der sogenannten Doppelgemeinden. Die Caesarische und Augusteische Kolonisation in Kleinasien. Vom Euphrat bis zum Bosporus, Kleinasien in der Antike, Festschrift für Elmar Schwertheim zum 65. Geburtstag. Asia Minor Studien, S. 65, C. 1 (Ed. E. Winter). Bonn: Dr. Rudolf Halberts Gmbh. s. 199-216.

Freber, P. S. (1993). Der Hellenistische Osten und das Illyricum unter Caesar (Palingenesia). Monographien und Texte zur Klasischen Altertumswissenschaft, S. 42. Stuttgart: Franz Steiner Verlag.

Filges, A. (2010). Lebensorte in der Fremde: Versuch einer Bewertung der RömischKleinasiatischen Kolonien von Caesar bis Diokletian. Militärsiedlungen und Territorialherrschaft in der Antike: Topoi-Berliner Studien der Alten Welt, S. 3 (Ed. F. Daubner). Berlin: De Gruyter. s. 131-154.

Filges, A. (2016). Münzbild und Gemeinschaft: Die Prägungen der Römischen Kolonien in Kleinasien. Frankfurter Archäologische Schriften, S. 29. Bonn: Rudolf Hulbert Verlag. 
Frisch, P. (1978). Die Inschriften von Lampsakos. Inschriften griechischer Städte aus Kleinasien, S. 6. Bonn: Rudolf Hulbert Verlag.

Galsterer-Kröll, B. (1972). Untersuchungen zu den Beinamen der Städte des Imperium Romanum. Epigraphische Studien, S. 9, s. 44-145.

Grant, M. (1946). From Imperium to Auctoritas: A Historical Study of Aes Coinage in the Roman Empire 49 B.C.- A.D. 14. Cambridge: University Press.

Henderson, M. I. (1953). Reviewed Work: F. Vittinghoff, Römische Kolonisation und Bürrerrechtpolitik unter Caesar und Augustus. Journal of Roman Studies, S. 43, s. 138-141.

Imhoof-Blumer, F. (1883). Monnaies Grecques. Amsterdam: Johannes Müller.

Imhoof-Blumer, F. (1884). Griechische Münzen aus dem Museum in Klagenfurt und anderen Sammlungen. Numismatische Zeitschrift, S. 16, s. 227-300.

Jiménez, A. - Carrillo, J. R. (2011). Corduba/Colonia Patricia: The Colony that was Founded Twice. Roman Colonies in the First Century of Their Foundation (Ed. R. J. Sweetman). Oakville: Oxbow Books. s. 55-74.

Jonnes, L. (1994). The Inscriptions of Heraclea Pontica. Inschriften griechischer Städte aus Kleinasien, S. 47. Bonn: Rudolf Hulbert Verlag.

Katsari, C. - Mitchell, S. (2008). The Roman Colonies of Greece and Asia Minor. Questions of State and Civic Identity. Athenaeum, S. 96, s. 221-249.

Koçyiğit, O. - Esirgemez, Ç. (2016). Lampsacus'da Geç Antik Bir Kırsal Yerleşim ve Şarap Üretim Atölyesi. Olba, S. 24, s. 439-478.

Körpe, R. (1998). 1996 Lapseki Kurtarma Kazısı. 8. Müze Kurtarma Kazıları Semineri. Ankara. s. 171- 194.

Körpe, R. - Treister, M. (2002). Rescue Excavation in the Necropolis of Lampsacus, 1996. Studia Troica, S. 12, s. 429-450.

Laffi, U. (2004a). Le Colonie Romane con I'appellativo Gemella o Gemina. Artissimum Memoriae Vinculum: Scritti di Geografia Storica e di Antichità in Ricordo di Gioia Conta (Ed. U. Laffi - F. Prontera - B. Virgilio). Frienze: Leo S. Olschki Editore. s. 235-254.

Laffi, U. (2004b). La Colonia Augustea di Alessandria di Troade. Colonie Romane nel Mondo Greco. Minima Epigraphica et Papyrologica, C. 3 (Ed. G. Salmeri - A. Raggi - A. Baroni). Roma: L'Erma di Bretscheneider. s. 151-164.

Laffi, U. (2007). Colonie e Municipi Nello Stato Romano. Storia e Letteratura: Raccolta di Studi e Testi, S. 239, Roma: Edizioni di Storia e Letteratura.

Levick, B. (1996). Greece (Including Crete and Cyprus) and Asia Minor from 43 B.C. to A.D. 69. The Cambridge Ancient History, S. 10 (Ed. A.K. Bowman - E. Champlin - A. lintott.). Cambridge: University Press. s. 641-675.

Martin, K. (2013a). Demos-Boule-Gerousia: Personifikationen Städtischer Institutionen auf Kaiserzeitlichen Münzen aus Kleinasien I. Bonn: Rudolf Hulbert Verlag.

Martin, K. (2013b). Demos-Boule-Gerousia: Personifikationen Städtischer Institutionen auf Kaiserzeitlichen Münzen aus Kleinasien II. Bonn: Rudolf Hulbert Verlag. 


\section{E. BURULDA $\breve{G}$}

Plinius. Natural History III-VII. Çev. H. Rackham, (1961), Cambridge: Harvard University Press.

Price, S. R. F. (2004). Ritüel ve İktidar: Küçük Asya'da Roma Imparatorluk Kültü. Çev. T. Esin. İstanbul: İmge Kitabevi.

Reid, J. S. (1913). The Municipalities of the Roman Empire. Cambridge: University Press.

Robert, J. - Robert, L. (1950). Inscriptions et Reliefs d'Asie Mineure. Hellenica: Recueil D’épigraphie de Numismatique et D'antiquités Grecques, S. 9. Paris: Librairie d'Amérique et d'Orient Adrien-Maisonneuve.

Robinson, E. S. G. (1921). Greek Coins from the Dardanelles. The Numismatic Chronicle and Journal of the Royal Numismatic Society, S. 1, N. 1/2, s. 1-25.

Römhild, J. H. (2011). Römische Bürger in der Troas. Studien zum Antiken Kleinasien VII. Asia Minor Studien, S. 66 (Ed. E. Schwertheim). Bonn: Dr. Rudolf Halberts Gmbh. s. 199-216.

RPC 1 Burnett, A. - Amandry, M. - Ripolles, P. P. (1992). Roman Provincial Coinage Vol. 1 (From the Death of Caesar to the Death of Vitellius) (44 BC-AD 69). Part III: Introduction and Catalogue. London: British Museum Press.

SNG v. Aulock. (1957). Sylloge Nummorum Gaecorum, Deutschland. Sammlung von Aulock, Mysien, S. 4. Berlin: Gebr. Mann Verlag.

SNG v. Aulock. (1967). Sylloge Nummorum Gaecorum, Deutschland. Sammlung von Aulock, Mysien, Troas, Aeolis, Lesbos, S. 16, Ek 2. Berlin: Gebr. Mann Verlag.

SNG Copenhagen. (1945). Sylloge Nummorum Graecorum. The Royal Collection of Coins and Medals, Danish National Museum, Mysia. Copenhagen: Eina Munksgaard.

SNG France 5. (2001). Sylloge Nummorum Graecorum, France 5. Départment des Monnaies, Médailles et Antiques: Mysie. Paris: Bibliothèque Nationale de France.

SNG Turkey 3. Tekin, O. - Altınoluk, S. - Körpe, F. (2009). Sylloge Nummorum Graecorum, Turkey, 3. Çanakkale Museum Vol. 1: Roman Provincial Coins of Mysia, Troas etc. İstanbul: Turkish Institute of Archaeology.

Strabon, Antik Anadolu Coğrafyası (Kitap XII-XIII-XIV). Çev. A. Pekman (2012). İstanbul: Arkeoloji ve Sanat Yayınları.

Tek, A. T. - Arslan, M. (1996). A Collection of Ancient Coins Mostly Acquired in Hellespont Area. Studies in Ancient Coinage from Turkey. Royal Numismatic Society Special Publication, S. 29 (Ed. R. Ashton). London: Royal Numismatic Society. s. 19-28.

Tenger, B. (1999). Zur Geographie und Geschichte der Troas. Die Troas. Neue Forschungen III. Asia Minor Studien, S. 33 (Ed. E. Schwertheim). Bonn: Dr. Rudolf Halberts Gmbh. s. 103-180.

Vittinghoff, F. (1952). Römische Kolonisation und Bürgerrechtspolitik. Mainz: Verlag der Akademie der Wissenschaften und der Literatur. 